\title{
Effect of two doses of a mixture of soluble fibres on body weight and metabolic variables in overweight or obese patients: a randomised trial
}

\author{
Jordi Salas-Salvadó $^{1 *}$, Xavier Farrés ${ }^{2}$, Xavier Luque $^{3}$, Silvia Narejos ${ }^{4}$, Manel Borrell ${ }^{5}$, Josep Basora ${ }^{6}$, \\ Anna Anguera $^{7}$, Ferran Torres ${ }^{8}$, Mònica Bulló ${ }^{1}$ and Rafel Balanza ${ }^{1}$, for the Fiber in Obesity-Study Group $\dagger$ \\ ${ }^{1}$ Human Nutrition Unit, Facultat de Medicina i Ciències de la Salut, Hospital Universitari de Sant Joan, Universitat Rovira $i$ \\ Virgili, C/Sant Llorenç 21, 43201 Reus, Spain \\ ${ }^{2}$ Centre d'Atenció Primària el Remei de Vic, Servei Català de la Salut, Barcelona, Spain \\ ${ }^{3}$ Centre d'Atenció Primària d'Alcover, Servei Català de la Salut, Barcelona, Spain \\ ${ }^{4}$ Centre d'Atenció Primària de Centelles, Servei Català de la Salut, Barcelona, Spain \\ ${ }^{5}$ Centre d'Atenció Primària Sarrià, Servei Català de la Salut, Barcelona, Spain \\ ${ }^{6}$ Centre d'Atenció Primària Reus I, Institut Català de la Salut, Reus, Spain \\ ${ }^{7}$ Research Department, Madaus, S.A., Barcelona, Spain \\ ${ }^{8}$ Laboratorio de Bioestadística y Epidemiologia, Servei de Farmacología Clínica, Hospital Clínic, Universitat Autònoma de \\ Barcelona, Barcelona, Spain
}

(Received 28 May 2007 - Revised 23 October 2007 - Accepted 25 October 2007 - First published online 22 November 2007)

The aim of the study was to compare the effect of the administration of a mixture of fibres on body weight-loss, satiety, lipid profile and glucose metabolism. We included 200 overweight or obese patients in a parallel, double-blind, placebo-controlled clinical trial, who were randomised to receive, in the context of an energy-restricted diet for a period of 16 weeks, a mixed fibre dose ( $3 \mathrm{~g}$ Plantago ovata husk and $1 \mathrm{~g}$ glucomannan) twice (b.i.d. group) or three times daily (t.i.d. group) or placebo. Weight change was the primary efficacy endpoint. Satiety, dietary compliance, lipid profile, glucose tolerance, insulin resistance and high-sensitivity C-reactive protein were secondary endpoints. Weight loss tended to be higher after both doses of fibre (-4.52 (SD 0.56) and -4.60 (SD 0.55) kg) than placebo (-0.79 (SD 0.58) kg); the differences in changes between groups were not statistically significant. Postprandial satiety increased in both fibre groups compared to the placebo. The differences between groups in LDL-cholesterol levels were significant $(P=0.03)$, with greater reductions in the two fibre-supplemented groups $(-0.38$ (SD 0.10$)$ and -0.24 (SD $0.09) \mathrm{mmol} / \mathrm{l}$ in the b.i.d. and t.i.d. groups $v$. -0.06 (SD 0.09) $\mathrm{mmol} / \mathrm{l}$ in placebo group). A similar pattern was observed for changes in total cholesterol:HDL-cholesterol and HDL-cholesterol:LDL-cholesterol ratios. Interventions were well tolerated and had no effects on HDL-cholesterol, glucose and insulin concentrations, glucose tolerance or high-sensitivity C-reactive protein. In conclusion, a 16-week dietary supplement of soluble fibre in overweight or obese patients was well tolerated, induced satiety and had beneficial effects on some CVD risk factors, the most important of which was a significant decrease in plasma LDL-cholesterol concentrations.

Dietary fibre: Glucomannan: Plantago: Body weight: Lipid profile

Excess energy intake is the primary dietary cause of obesity, although other dietary factors need to be taken into account. Nutritional guidelines recommend dietary fibre for health promotion and disease prevention. However, the beneficial effects of dietary fibre in the prevention, or treatment, of obesity and associated metabolic disturbances are not consistent.

Obesity and diabetes are less prevalent in populations consuming large amounts of dietary fibre. Further, excess weight and obesity were substantially lower in vegetarian populations ${ }^{(1)}$, suggesting that fibre intake could play an important role in the prevention and progression of these metabolic conditions. Cross-sectional studies have shown that, following adjustment for confounding variables, the intakes of total fibre and soluble fibre are inversely related to total fat intake, bodyfat content and BMI. Obese subjects typically consume less fibre than normal-weight individuals ${ }^{(2)}$. In a 10-year prospective study in young adults, fibre intake was associated with lower weight increases and a lower risk of developing obesity, after adjustment for fat intake ${ }^{(3)}$.

Several mechanisms have been proposed to explain the role of fibre intake on body-weight regulation ${ }^{(4)}$, apart from displacing energy and nutrients from the diet. Fibre increases the volume of gastric contents, reduces gastric emptying and promotes satiation ${ }^{(5,6)}$ while decreasing the absorption of

Abbreviations: b.i.d., experimental treatment with mixed fibre dose given twice daily; t.i.d., experimental treatment with mixed fibre dose given three times daily; HOMA-IR, homeostasis model assessment of insulin resistance; ITT, intention-to-treat; OGTT, oral glucose tolerance test.

* Corresponding author: Dr J. Salas-Salvadó, fax +34977 7593 22, email jordi.salas@urv.cat

$\dagger$ The investigators participating in the Fiber in Obesity-Study Group are listed in the Acknowledgements. 
macronutrients ${ }^{(7)}$ and influencing the secretion of gut hormones controlling fat oxidation and storage ${ }^{(8)}$.

Epidemiological data and mechanistic studies support the beneficial effects of fibre in body-weight regulation, but data from randomised controlled clinical trials evaluating the effect of fibre supplementation of the diet on body weight have not been consistent ${ }^{(9-12)}$. In a systematic review, Howarth et al. analysed several clinical trials conducted in small and heterogeneous population samples over relatively short periods of time ${ }^{(13)}$. The findings were that the intake of $12 \mathrm{~g}$ fibre/d resulted in a decrease of $10 \%$ in energy intake and a body-weight loss of $1.9 \mathrm{~kg}$ over 3.8 months. These authors indicated that this effect on body-weight loss was greater in obese subjects.

However, long-term compliance to fibre supplementation of the diet is poor in adults ${ }^{(14)}$. If fibre is to be considered a longterm therapeutic option, an effective and well-tolerated source needs to be found.

The aim of our study was to evaluate the effect of a 16-week consumption of a new fibre mixture on weight loss, tolerance, satiety, the lipid profile, glucose metabolism and high-sensitivity C-reactive protein in overweight (or obese) patients attending primary care centres.

\section{Material and methods}

\section{Subjects}

Male and female patients between the ages of 18 and 70 years who were overweight or obese $\left(27<\mathrm{BMI}<35 \mathrm{~kg} / \mathrm{m}^{2}\right)$ with a high degree of motivation to achieve weight loss were invited to participate in a parallel, double-blind, randomised placebocontrolled, multi-centred clinical trial using two dose levels of a mixture of fibre. Patients were recruited from eleven primary care centres in Spain. Exclusion criteria for the study were: (1) diabetes mellitus requiring treatment with anti-diabetic drugs or insulin, or other known endocrine disorders; (2) dyslipidaemia requiring pharmacological treatment according to the National Cholesterol Education Program Adult Treatment Panel III (ATP III) guidelines; (3) intake of anti-obesity medication and/or following a low-energy diet over the 8 weeks prior to entry into the present study; (4) previous bariatric surgery; (5) history of eating disorders; (6) intake of dietary fibre supplements in the month prior to inclusion in the present study; (7) acute or chronic infection, inflammatory disease or cancer. The Institutional Review Board of the eleven participating primary care centres approved the study protocol. Written informed consent was obtained from all patients participating in the study.

\section{Study design and intervention}

At the initial visit, a complete medical history and physical examination of the patient was taken. Before randomisation the subjects were stratified by gender and BMI (BMI $\leq 30 \mathrm{~kg} /$ $\mathrm{m}^{2}$ or $\mathrm{BMI}>30 \mathrm{~kg} / \mathrm{m}^{2}$ ). Eligible subjects were assigned to receive fibre (at two fixed doses) or placebo in a 2:1 ratio for each dose level for a 16 -week period. A randomisation list was computer generated in a fixed block size of six patients. The details of the randomisation codes were kept in sealed envelopes away from the investigator. Only in cases of the utmost necessity (e.g. serious adverse events) was the assignment of the patient made known to the investigator by the study co-ordinator. Patients, investigators, monitors and statisticians were blinded with respect to the treatment assignment.

All enrolled patients were individually advised to follow a diet that was reduced by $2.5 \mathrm{MJ} / \mathrm{d}$ compared to their current diet, as recommended by the National Heart Lung and Blood Institute ${ }^{(15)}$ and the Spanish Consensus on obesity $(<35,>45$ and $<25 \%$ of total energy intake in the form of fat, carbohydrates and protein respectively $)^{(16)}$. No participant received a diet containing $<4.1 \mathrm{MJ} / \mathrm{d}$ during the course of the study. Depending on the assigned group, the patients received either a fibre-mix product, or a placebo product twice daily (b.i.d.) or three times daily (t.i.d.), taken with $150 \mathrm{ml}$ water $10 \mathrm{~min}$ before lunch and dinner (b.i.d. group) or breakfast, lunch and dinner (t.i.d. group), respectively.

The fibre supplement and the placebo were administered as soluble effervescent powder in sachets (manufactured by Madaus, S.A.) of identical weight and presentation. Each sachet of the fibre supplement contained $3 \mathrm{~g}$ Plantago ovata seed husks and $1 \mathrm{~g}$ glucomannan. The placebo sachets contained $3 \mathrm{~g}$ microcrystalline cellulose.

\section{Measurements}

With the patient wearing light clothes, weight was measured with a $\pm 100 \mathrm{~g}$ precision at baseline and every 4 weeks until the study was completed. Weight difference between baseline and final visit was considered the primary efficacy endpoint. Other variables measured at baseline and after 16 weeks of treatment were self-assessment of satiety and adherence to diet and treatment, lipid profile (total cholesterol, VLDL-, LDL- and HDL-cholesterol and TAG), fasting glucose and insulin, oral glucose tolerance test (OGTT), homeostasis model assessment of insulin resistance (HOMA-IR) index, fasting glycosylated $\mathrm{Hb}$ and serum high-sensitivity C-reactive protein.

At baseline, and after 8 and 16 weeks of treatment, patients were asked to determine and record in a diary, the level of postprandial satiety on the day of the consultation visit plus $2 \mathrm{~d}$ prior to the visit, on a $100 \mathrm{~mm}$ visual analogue scale. In the same diary, the patient recorded the self-assessment of level of adherence to the diet on a $100 \mathrm{~mm}$ visual analogue scale. The investigator monitored treatment compliance by counting the medication sachets returned by the patient at each follow-up visit at weeks 4, 8, 12 and 16.

Fasting blood samples were taken between 08.00 and 09.00 hours at baseline and at the end of the study. Biochemical parameters were assessed by routine methods. Fasting insulin was centrally measured by radioimmunoassay using a commercial kit (Immundiagnostik AG, Bensheim, Germany). The lower limit of detection was $0.1 \mathrm{mg} / \mathrm{l}$ and the intra- and inter-assay $\mathrm{CV}$ were 0.9 and $1.7 \%$, respectively. Insulin resistance was assessed by HOMA-IR as follows: fasting plasma insulin $(\mathrm{mIU} / \mathrm{l}) \times$ the fasting plasma glucose $(\mathrm{mmol} / \mathrm{l})$ divided by 22.5. Serum high-sensitivity C-reactive protein concentrations were also centrally measured using commercial enzymelinked immunosorbent assay kits (Alpha Diagnostic International, Texas, USA). Intra- and inter-assay CV were $<10 \%$. OGTT was performed following a $75 \mathrm{~g}$ glucose load 
in fasting conditions at baseline and after 16 weeks of treatment.

Information on adverse events possibly related to the dietary supplement products was solicited at each visit to the clinic during the study period. At each visit the patients were asked an open-ended question regarding any unusual symptoms, or discomfort, or side effects such as more defaecation, flatulence, or any other events over the previous weeks.

\section{Statistical methods}

Based on $80 \%$ power to detect a significant difference of 1.5 (SD 2.66) $\mathrm{kg}$ in weight reduction, type 1 error $(\alpha)=0.05$ (twosided), fifty-one valid patients were required for each study group. We randomised a total of 200 patients to compensate for non-measurable patients. Of the 200 randomised patients, 185 were included in the safety analysis, 166 in the intention-to-treat (ITT) analysis, and 126 in the per-protocol analysis. The results are expressed as mean, standard deviation and/or $95 \% \mathrm{CI}$, or as a percentage. The primary and secondary efficacy variables were evaluated by an ANCOVA model using the baseline value and the BMI stratum as covariates. Between-groups comparisons for the rest of the variables were performed using the Fisher exact test or ANOVA, according to the nature of the variables. The last-observation carried-forward approach was applied for the main outcome; the rest of variables were analysed according to the available-data-only approach. The analysis was performed following the ITT principle, using SAS version 9.1.3 software (SAS Institute Inc., Cary, NC, USA), and the level of significance was established at $P=0.05$ (two-sided). We show the results of the ITT analysis because no significant differences in the results were found between the ITT and the per-protocol analysis.

\section{Results}

\section{Patients}

Two hundred adult patients were randomised and assigned to the three treatment groups (t.i.d. group, $n 68$; b.i.d. group, $n 66$; placebo group $n$ 66). Of these, thirty-three patients were not included in the ITT analysis: nine due to withdrawal of informed consent, five due to selection criteria violation, and nineteen due to the lack of some measurable variables at baseline or due to other reasons. Subsequent data refers only to the 166 patients of the ITT study population (t.i.d. group, $n$ 58; b.i.d. group, $n 53$; placebo group, $n 55)$. There were no statistically significant differences among treatment groups with respect to timeon-treatment or causes for discontinuing the study. Table 1 summarises the baseline characteristics of the 166 measurable patients ( $22 \%$ men and $78 \%$ women). The three groups were well balanced in terms of age, gender, weight and BMI. No significant differences were observed between groups in relation to the plasma lipid profile, fasting glucose, insulin or glycosylated $\mathrm{Hb}$ concentrations or glucose tolerance at the beginning of the study. None of the groups showed significant differences in relation to the degree of postprandial satiety.

Adherence to the treatment (monitored by the investigator by counting the medication sachets returned by the patient at each follow-up visit) and to the diet (evaluated by the patient on the visual analogue scale at each follow-up visit) in all the groups was, in general, very high $(>90 \%$ in all the consultation visits). No statistically significant differences were found among groups in relation to treatment compliance or to the self-assessment of the level of adherence to the diet.

\section{Changes produced following the intervention}

Weight loss was observed with both fibre doses $(-4.52$ (SD 0.56) $\mathrm{kg}$ in the b.i.d. group and -4.60 (SD 0.55) $\mathrm{kg}$ in

Table 1. Characteristics of the subjects on entry into the trial*

(Values are means with standard deviations)

\begin{tabular}{|c|c|c|c|c|c|c|c|c|}
\hline & \multicolumn{2}{|c|}{ b.i.d. group ( $n$ 53) } & \multicolumn{2}{|c|}{ t.i.d. group ( $n$ 58) } & \multicolumn{2}{|c|}{ Placebo (n 55) } & \multicolumn{2}{|c|}{ Total (n 166) } \\
\hline & Mean & SD & Mean & SD & Mean & SD & Mean & SD \\
\hline Age (years) & $47 \cdot 1$ & $12 \cdot 5$ & $50 \cdot 1$ & $11 \cdot 6$ & $46 \cdot 4$ & 11.9 & $47 \cdot 9$ & $12 \cdot 0$ \\
\hline Men (\%) & \multicolumn{2}{|c|}{$20 \cdot 8$} & \multicolumn{2}{|c|}{$20 \cdot 7$} & \multicolumn{2}{|c|}{23.6} & \multicolumn{2}{|c|}{$21 \cdot 7$} \\
\hline Women (\%) & \multicolumn{2}{|c|}{$79 \cdot 2$} & \multicolumn{2}{|c|}{$79 \cdot 3$} & \multicolumn{2}{|c|}{$76 \cdot 4$} & \multicolumn{2}{|c|}{$78 \cdot 3$} \\
\hline Weight (kg) & $79 \cdot 7$ & $11 \cdot 0$ & $80 \cdot 6$ & $11 \cdot 3$ & $83 \cdot 7$ & $11 \cdot 6$ & $81 \cdot 3$ & $11 \cdot 3$ \\
\hline BMI $\left(\mathrm{kg} / \mathrm{m}^{2}\right)$ & $31 \cdot 2$ & $2 \cdot 3$ & $31 \cdot 0$ & $2 \cdot 4$ & $31 \cdot 2$ & $2 \cdot 3$ & $31 \cdot 2$ & $2 \cdot 3$ \\
\hline Glycosylated Hb (\%) & 4.6 & 0.4 & $4 \cdot 7$ & 0.4 & $4 \cdot 8$ & 0.6 & $4 \cdot 7$ & 0.5 \\
\hline Fasting glucose $(\mathrm{mmol} / \mathrm{l})$ & $5 \cdot 1$ & 0.8 & $5 \cdot 1$ & 0.7 & $5 \cdot 1$ & 0.8 & $5 \cdot 1$ & 0.7 \\
\hline Glucose $2 \mathrm{~h}$ OGTT $(\mathrm{mmol} / \mathrm{l})$ & $5 \cdot 6$ & $2 \cdot 1$ & $5 \cdot 4$ & 1.9 & $5 \cdot 4$ & $2 \cdot 1$ & $5 \cdot 5$ & $2 \cdot 0$ \\
\hline Fasting insulin (pmol/l) & 63.6 & $67 \cdot 0$ & $66 \cdot 1$ & $62 \cdot 2$ & $50 \cdot 5$ & $37 \cdot 4$ & $60 \cdot 1$ & $56 \cdot 9$ \\
\hline HOMA-IR & 2.08 & 2.44 & 2.05 & 1.63 & 1.64 & $1 \cdot 27$ & 1.92 & 1.83 \\
\hline Total cholesterol (mmol/l) & $5 \cdot 2$ & 0.9 & $5 \cdot 3$ & 0.9 & $5 \cdot 3$ & $1 \cdot 1$ & $5 \cdot 3$ & $1 \cdot 0$ \\
\hline LDL-cholesterol (mmol/l) & 3.4 & 0.8 & 3.4 & 0.8 & 3.4 & 0.9 & $3 \cdot 4$ & 0.8 \\
\hline HDL-cholesterol (mmol/l) & $1 \cdot 3$ & 0.3 & 1.3 & 0.3 & 1.4 & 0.4 & $1 \cdot 3$ & 0.4 \\
\hline Total cholesterol:HDL-cholesterol & $4 \cdot 3$ & $1 \cdot 1$ & 4.2 & $1 \cdot 1$ & $4 \cdot 1$ & 1.4 & $4 \cdot 2$ & $1 \cdot 2$ \\
\hline HDL-cholesterol:LDL-cholesterol & 0.40 & 0.16 & 0.42 & $0 \cdot 18$ & 0.43 & $0 \cdot 16$ & 0.42 & 0.17 \\
\hline TAG $(\mathrm{mmol} / \mathrm{l})$ & $1 \cdot 2$ & 0.5 & 1.4 & 0.8 & $1 \cdot 1$ & 0.6 & $1 \cdot 2$ & 0.7 \\
\hline hs-CRP (mg/l) & 0.75 & 1.39 & 0.86 & 0.73 & 0.70 & 0.51 & 0.77 & 0.88 \\
\hline
\end{tabular}

b.i.d., mixed fibre dose given twice daily; t.i.d., mixed fibre dose given three times daily; OGGT, oral glucose tolerance test; HOMA-IR, homeostasis model assessment of insulin resistance; hs-CRP, high-sensitivity C-reactive protein.

* There were no significant differences between groups. 
the t.i.d. group) and with the placebo $(-3.79(\mathrm{SD} 0.58) \mathrm{kg}$ ) at the end of 16 weeks of the study. The weight loss was progressive and constant in the three study groups, without any weight regained at the end of the study. Although the changes tend to be greater in both groups supplemented with dietary fibre, the differences between groups were not statistically significant $(P=0.43)$ (Fig. 1)

Table 2 summarises the effect of interventions on the measured plasma biochemical parameters. During the 16 weeks of the trial, glycosylated $\mathrm{Hb}$ decreased within all three groups $(-0.03$ (SD 0.06) in the b.i.d. group, -0.11 (SD 0.06 ) in the t.i.d. group and -0.15 (SD 0.06) in the placebo group); the differences between the groups not being statistically significant. Fasting glucose and $2 \mathrm{~h}$ post-OGTT decreased within all three groups with the exception of the fasting glucose in the placebo group (fasting glucose changed -0.12 (SD 0.11), -0.09 (SD 0.10), 0.03 (SD 0.10) $\mathrm{mmol} / \mathrm{l}$ and glucose $2 \mathrm{~h}$ post OGTT changed -0.20 (SD 0.29), $-0 \cdot 17$ (SD 0.26 ) and $-0.24(\mathrm{SD} 0.27) \mathrm{mmol} / \mathrm{l}$ in the b.i.d., t.i.d. and placebo groups, respectively). Fasting insulin and $2 \mathrm{~h}$ post-OGTT decreased considerably within the b.i.d. group, albeit the changes between groups were not statistically significant. No significant differences in changes on HOMA-IR index were observed among the groups. However, the changes in the lipid profile induced by the interventions were different between groups. The decrease in plasma total cholesterol tended to be greater in the b.i.d. and t.i.d. groups compared to placebo. The differences between groups with respect to the plasma LDL-cholesterol concentrations were statistically significant $(P=0.03)$, with a greater decrease observed in the two fibre-supplemented groups $(-0.38$ (SD 0.10) and -0.24 (SD 0.09) $\mathrm{mmol} / \mathrm{l}$ in the b.i.d. and t.i.d. groups $v$. -0.06 (SD 0.09) $\mathrm{mmol} / \mathrm{l}$ in placebo), although no dose-response pattern was observed for this parameter. The changes in HDLcholesterol and TAG concentrations did not follow any clear trend within or between the intervention groups. The differences between groups in the plasma total cholesterol:HDLcholesterol and HDL-cholesterol:LDL-cholesterol ratio were

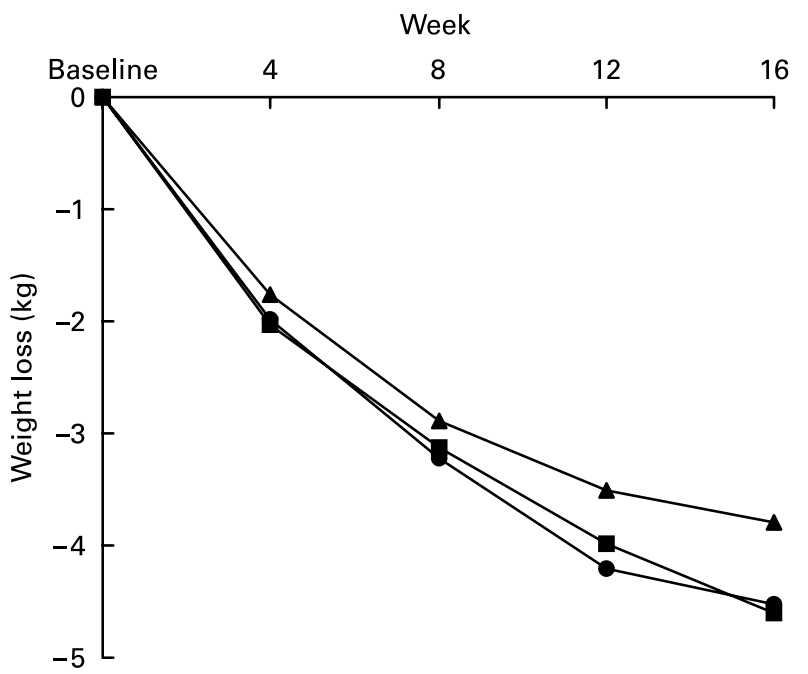

Fig. 1. Effects on body weight of the 16-week fibre supplementation in b.i.d group (mixed fibre dose given twice daily, - $\bullet-$ ) and t.i.d. group (mixed fibre dose given three times daily, $-\mathbf{\square}-$ ) compared with placebo, $-\mathbf{\Delta}-$. No statistically significant differences in changes were observed between groups. statistically significant $(P=0.03$ and $P=0.02$, respectively, with a greater change observed in the two fibre-supplemented groups). No differences between groups were observed in relation to serum $\mathrm{C}$-reactive protein concentrations. Table 3 summarises the observed effects of the 16-week fibre supplementation on perceived satiety. The differences between groups in changes in satiety were statistically significant post-lunch $(P=0.04)$ but not post-dinner. However, no significant differences in satiety were observed between the two fibre-supplemented groups.

\section{Safety}

No serious adverse event was reported during the study. No significant differences in total adverse events were observed between groups. Gastrointestinal complaints (3.8\% diarrhoea, $32.2 \%$ flatulence, $2.2 \%$ constipation, $2.2 \%$ upper abdominal pain and $0.5 \%$ abdominal distension) were the most frequently reported adverse events, with no significant differences in the proportions of these events reported between the treatment groups. There were no patient withdrawals from the study due to adverse events.

\section{Discussion}

The results of our study suggest that fibre supplementation, in the context of a weight-reducing diet, could be beneficial in overweight or obese individuals because the additional fibre induces satiety and a more long-term favourable lipoprotein profile than placebo. However, the present results do not support the hypothesis that fibre supplements in combination with a conventional energy intake restriction can have additional effects on weight reduction and glucose tolerance.

The literature contains several reports of the effect of fibre supplements on body weight ${ }^{(9,13)}$. However, in few of the randomised placebo-controlled clinical trials has the body weight been considered the primary variable in the analysis ${ }^{(4)}$. In addition, long-term ( $\geq 4$ months) trials are rare (17-20) $^{\text {and }}$ have been conducted in small samples of heterogeneous populations (healthy controls, obese or diabetic patients) while using different types and doses of fibre ${ }^{(13)}$.

To the best of our knowledge, our study is unique in analysing the effect of two doses of soluble-fibre supplementation on body weight and/or other metabolic variables. Because of the great variability expected in the response of body weight following intervention, our study was performed in 200 individuals. Hence, the present study is one of the few large-scale studies analysing the long-term effects of a supplement of fibre on lipid profile, glucose tolerance ${ }^{(21)}$, bodyweight changes and satiety.

The influence of dietary-fibre supplements on energy regulation remains controversial ${ }^{(4)}$. One of the best-studied supplements of fibre on body weight is guar gum. A metaanalysis of the randomised placebo-controlled trials identified thirty-four guar gum trials of which only eleven could be analysed $^{(9)}$ and only two were for a period $>14$ weeks $^{(17,20)}$. The meta-analysis concluded that guar gum is not efficacious for reducing body weight and is frequently associated with gastrointestinal complaints such as flatulence, diarrhoea, abdominal pain, and cramps ${ }^{(9)}$. 
Other types of fibre supplements have been studied, also with inconclusive results with respect to weight control ${ }^{(22-24)}$. Among these fibres, Plantago ovata and glucomannan are the most relevant. As with the results of our study, a previous large-scale study performed with ispaghula husk showed no significant short-term (3 weeks) differences in body-weight loss when comparing isphaghula, bran and control groups ${ }^{(22)}$. Also as with the present study, a decrease in hunger ratings

Table 2. Effects of 16-week fibre supplementation on plasma metabolic markers* (Values are means with standard deviations and means with $95 \% \mathrm{Cl}$ )

\begin{tabular}{|c|c|c|c|c|c|}
\hline & \multicolumn{2}{|c|}{ Change† (n 166) } & \multicolumn{2}{|c|}{ Differencesł } & \multirow[b]{2}{*}{$P \S$} \\
\hline & Mean & SD & Mean & $95 \% \mathrm{Cl}$ & \\
\hline Glycosylated Hb (\%) & & & & & 0.34 \\
\hline b.i.d. group & -0.03 & 0.06 & 0.12 & $-0.04,0.28$ & \\
\hline t.i.d. group & $-0 \cdot 11$ & 0.06 & 0.04 & $-0.12,0.19$ & \\
\hline Placebo group & -0.15 & 0.06 & & & \\
\hline Fasting glucose (mmol/l) & & & & & 0.48 \\
\hline b.i.d. group & -0.12 & $0 \cdot 11$ & -0.15 & $-0.42,0.12$ & \\
\hline t.i.d. group & -0.09 & $0 \cdot 10$ & -0.12 & $-0.38,0.13$ & \\
\hline Placebo group & 0.03 & $0 \cdot 10$ & & & \\
\hline Glucose $2 \mathrm{~h}$ OGTT (mmol/l) & & & & & 0.97 \\
\hline b.i.d. group & -0.20 & 0.29 & 0.04 & $-0.64,0.72$ & \\
\hline t.i.d. group & -0.17 & 0.26 & 0.07 & $-0.58,0.72$ & \\
\hline Placebo group & -0.24 & 0.27 & & & \\
\hline Fasting insulin $(\mathrm{pmol} / \mathrm{l})$ & & & & & 0.37 \\
\hline b.i.d. group & -22.04 & $7 \cdot 24$ & $-10 \cdot 20$ & $-27 \cdot 13,6 \cdot 74$ & \\
\hline t.i.d. group & $-11 \cdot 26$ & $6 \cdot 76$ & 0.59 & $-15 \cdot 71,16 \cdot 89$ & \\
\hline Placebo group & -11.85 & $6 \cdot 57$ & & & \\
\hline Insulin 2 h OGTT (pmol/l) & & & & & 0.62 \\
\hline b.i.d. group & -41.06 & $26 \cdot 37$ & $-28 \cdot 37$ & $-91 \cdot 62,34 \cdot 87$ & \\
\hline t.i.d. group & $-15 \cdot 79$ & 24.65 & $-3 \cdot 10$ & $-62 \cdot 68,56.47$ & \\
\hline Placebo group & -12.69 & 24.65 & & & \\
\hline HOMA-IR & & & & & 0.32 \\
\hline b.i.d. group & -0.71 & 0.23 & -0.40 & $-0.93,0.14$ & \\
\hline t.i.d. group & -0.42 & 0.21 & -0.11 & $-0.62,0.40$ & \\
\hline Placebo group & -0.31 & 0.30 & & & \\
\hline Total cholesterol $(\mathrm{mmol} / \mathrm{l})$ & & & & & 0.07 \\
\hline b.i.d. group & -0.43 & 0.12 & -0.32 & $-0.60,0.04$ & \\
\hline t.i.d. group & -0.33 & 0.11 & -0.22 & $-0.49,0.05$ & \\
\hline Placebo group & -0.11 & 0.11 & & & \\
\hline LDL-cholesterol (mmol/l) & & & & & 0.03 \\
\hline b.i.d. group & -0.38 & $0 \cdot 10$ & -0.32 & $-0.56,-0.07$ & \\
\hline t.i.d. group & -0.24 & 0.09 & -0.18 & $-0.41,0.05$ & \\
\hline Placebo group & -0.06 & 0.09 & & & \\
\hline HDL-cholesterol (mmol/l) & & & & & 0.44 \\
\hline b.i.d. group & -0.01 & 0.04 & 0.05 & $-0.04,0.14$ & \\
\hline t.i.d. group & -0.06 & 0.03 & -0.01 & $-0.09,0.08$ & \\
\hline Placebo group & -0.05 & 0.03 & & & \\
\hline Total cholesterol:HDL-cholesterol & & & & & 0.03 \\
\hline b.i.d. group & -0.36 & 0.14 & -0.44 & $-0.76,-0.12$ & \\
\hline t.i.d. group & -0.13 & 0.12 & -0.21 & $-0.51,0.09$ & \\
\hline Placebo group & 0.07 & $0 \cdot 12$ & & & \\
\hline HDL-cholesterol:LDL-cholesterol & & & & & 0.02 \\
\hline b.i.d. group & 0.06 & 0.02 & 0.06 & $0.02,0.11$ & \\
\hline t.i.d. group & 0.02 & 0.02 & 0.02 & $-0.02,0.06$ & \\
\hline Placebo group & -0.01 & 0.02 & & & \\
\hline $\mathrm{TAG}(\mathrm{mmol} / \mathrm{l})$ & & & & & 0.43 \\
\hline b.i.d. group & -0.03 & 0.26 & -0.36 & $-0.97,0.25$ & \\
\hline t.i.d. group & -0.01 & 0.23 & -0.32 & $-0.9,0.26$ & \\
\hline Placebo group & 0.33 & 0.23 & & & \\
\hline hs-CRP (mg/l) & & & & & \\
\hline b.i.d. group & -0.10 & 0.15 & -0.12 & $-0.42,0.18$ & 0.34 \\
\hline t.i.d. group & -0.08 & $0 \cdot 10$ & -0.10 & $-0.32,0.12$ & \\
\hline Placebo group & 0.02 & 0.05 & & & \\
\hline
\end{tabular}

b.i.d., mixed fibre dose given twice daily; t.i.d., mixed fibre dose given three times daily; OGGT, oral glucose tolerance test; HOMA-IR, homeostasis model assessment of insulin resistance.

* Results from the ANCOVA model. All results are adjusted by stratum and baseline values.

† Changes between start and end of study.

$\ddagger$ Differences in changes between groups (b.i.d. and t.i.d. v. placebo).

$\S$ Statistical differences in changes between groups. 
Table 3. Effects of 16-week fibre supplementation on satiety*

(Values are means with standard deviations and means with $95 \% \mathrm{Cl}$ )

\begin{tabular}{|c|c|c|c|c|c|}
\hline & \multicolumn{2}{|c|}{ Change† ( $n$ 166) } & \multicolumn{2}{|c|}{ Differences $\ddagger$} & \multirow[b]{2}{*}{$P \S$} \\
\hline & Mean & SD & Mean & $95 \% \mathrm{Cl}$ & \\
\hline Satiety post-lunch & & & & & 0.04 \\
\hline b.i.d. group & $5 \cdot 14$ & 4.53 & 13.57 & $2 \cdot 61,24.54$ & \\
\hline t.i.d. group & 1.07 & $4 \cdot 17$ & $9 \cdot 50$ & $-1.06,20.07$ & \\
\hline Placebo group & -8.43 & $4 \cdot 29$ & & & \\
\hline Satiety post-dinner & & & & & 0.16 \\
\hline b.i.d. group & 2.54 & $4 \cdot 81$ & $10 \cdot 40$ & $-1 \cdot 25,22.05$ & \\
\hline t.i.d. group & 1.06 & 4.43 & 8.92 & $-2 \cdot 31,20 \cdot 16$ & \\
\hline Placebo group & $-7 \cdot 87$ & 4.57 & & & \\
\hline
\end{tabular}

b.i.d., mixed fibre dose given twice daily; t.i.d., mixed fibre dose given three times daily.

* Results from the ANCOVA model. All results are adjusted by stratum and baseline values.

† Changes between start and end of the study.

$\ddagger$ Differences in changes between groups (b.i.d. and t.i.d. $v$. placebo).

$\S$ Statistical differences in changes between groups.

was observed at the end of the study period compared to the baseline values in both groups receiving the fibre supplements ${ }^{(22)}$. No significant short-term effects (6 weeks) of $5 \mathrm{~g}$ Plantago psyllium on body weight had been observed in type II diabetic patients when evaluating the lipid- and glucose-lowering efficacy of this type of fibre ${ }^{(10)}$. In contrast several studies have demonstrated a significant effect of glucomannan supplements on appetite and body weight. However, only some of these studies were randomised placebocontrolled trials, and all were short-term and performed in small study populations ${ }^{(24-27)}$. In our study, the two groups receiving the dietary fibre tended towards greater weight loss than did control individuals. However, the lack of significant differences in body-weight loss observed between groups does not support the hypothesis that this type of fibre has any effect on body weight. Whether significant differences would be observed by increasing the fibre dose is worth considering in future studies.

As with guar gum, isphagula husk (another viscous soluble fibre), has also been associated with gastrointestinal secondary adverse effects because of the rapid fermentation when the fibres arrive intact in the colon ${ }^{(9)}$. In a previous study, we observed that a mixture of Plantago ovata combined with glucomannan slows fermentation in the colon and retards the rate of butyrate and propionate production in vitro (L Fluvià and $\mathrm{A}$ Anguera, unpublished results). For this reason, we propose that the intake of this fibre mixture increases subject compliance due to fewer gastrointestinal side effects associated with the delay in gas production, which increases the patient's tolerance of the mixture. It is for this reason that we selected to study the effects of a mixture of these two types of fibre: Plantago ovata husks and glucomannan. In the present study the dietary fibre supplement was well tolerated by the patients. Gastrointestinal symptoms were the most frequent adverse events reported in our study but these were not of any clinical significance. Also, there were no significant differences observed between the groups taking the fibre and the placebo group. As such, our study suggests that long-term administration of Plantago ovata and glucomannan has a high patient-acceptability.
With respect to changes in the lipid profile, our results are in the same direction of a previously-published meta-analysis analysing this effect. We observed a greater decrease in plasma total cholesterol in both groups of patients receiving the fibre. These differences were due, in part, to significant decreases in the plasma LDL-cholesterol concentrations observed in the two groups receiving the fibre compared to the placebo group $(-0.38$ (SD 0.10) and -0.24 (SD 0.09) $\mathrm{mmol} / \mathrm{l}$ in the b.i.d. and t.i.d. groups $v$. -0.06 (SD 0.09) $\mathrm{mmol} / \mathrm{l}$ in placebo group). The hypocholesterolaemic effect observed was modest, not dependent on the dose administered, and of the same magnitude as that observed in a meta-analysis where the decrease in total and LDL-cholesterol was estimated to be about $0.05 \mathrm{mmol} / \mathrm{l}$ for every gram of soluble fibre added to the diet ${ }^{(21,28)}$. As with the conclusions of the meta-analysis cited earlier, our study suggests that the intake of a fibre supplement has no effect on HDL-cholesterol or TAG concentrations. Of note is that obesity is associated with atherogenic dyslipidemia, which has been considered an important CVD risk factor. Hence, fibre supplementation in the context of a weight-reducing diet could decrease the cardiovascular risk in obese people through the mechanism of LDL-cholesterol reduction i.e. $1 \%$ decrease in plasma LDL-cholesterol is estimated to result in a $2 \%$ decrease in coronary disease mortality. Our results highlight significant differences between groups in relation to the changes in the plasma total cholesterol:HDL-cholesterol and HDL-cholesterol:LDLcholesterol ratios with more favourable changes induced in the two fibre-supplemented groups compared to placebo.

In relation to glucose metabolism, population studies have shown that high-fibre diets may play a protective role in the prevention of type 2 diabetes ${ }^{(29,30)}$ and $\mathrm{CVD}^{(31)}$. Diets that are high in complex carbohydrates and fibre were shown to be associated with greater insulin sensitivity and a reduction in plasma insulin levels. Also, high-fibre diets contribute to a better metabolic control in diabetic subjects ${ }^{(32)}$. However, some clinical studies have shown that only the viscous variety of some soluble fibres play a significant role in reducing postprandial glycaemia ${ }^{(33)}$. In our study, the fibre supplements showed no significant effects on insulin resistance, fasting glucose and post-OGTT glucose or insulin concentrations, or glycosylated $\mathrm{Hb}$. This is probably because none of the patients studied had diabetes requiring oral antidiabetic drugs or insulin.

There is a lack of consensus in the literature with regard to the anti-inflammatory effects of fibre. Results from two epidemiological studies indicated that dietary-fibre intake was inversely associated with serum C-reactive protein concentrations ${ }^{(34,35)}$, but another large study failed to find any association between whole-grain intake and plasma C-reactive protein, IL-6 or fibrinogen concentrations ${ }^{(36)}$. In our study, we were unable to demonstrate any effect of the additional dietary fibre consumption on plasma high-sensitivity C-reactive protein concentrations, although patients receiving the fibre tended to have greater decreases in this parameter.

In conclusion, the present study shows that the administration over a protracted period of 16 weeks of a supplement of a soluble fibre mixture of Plantago ovata and glucomannan to overweight or obese patients induced satiety and a decrease in plasma LDL-cholesterol concentrations, without any effect observed on body weight, TAG, HDL-cholesterol concentrations or other glucose metabolism parameters. 


\section{Acknowledgements}

This study was supported by MADAUS, S.A. and by the Instituto de Salud Carlos III (Thematic Network G03/140 and RD06/0045, and PI051839), Spain. Dr Salas-Salvadó and Dr Ferrán Torres have received consulting or lecture fees from Madaus Laboratories. Dr Anguera belongs to Madaus Laboratory. The order in which the authors are listed has been agreed on by the investigators. Jordi Salas-Salvadó, Rafel Balanza, Mònica Bulló, Ferrán Torres and Anna Anguera have made the greatest contribution, and wrote the preliminary version. All the authors have contributed equally to the work by discussing and analysing the data and writing the definitive version.

The following investigators and co-investigators participated in the study: Unitat de Nutrició Humana: Jordi SalasSalvadó, Mònica Bulló, Rafel Balanza, Patricia Casas, Fabiola Márquez. CAP el Remei de Vic: Xavier Farrés, CAP d'Alcover: Xavier Luque, CAP de Centelles: Silvia Narejos, CAP Sarrià, Barcelona: Manel Borrell, CAP Reus I: Josep Basora, CAP Sardenya: Carles Brotons, CAP Sant Gervasi (Parc Sanitari Pere Virgili): Anna Altés, CAP Les HortesPoble Sec: Cristina González Fernández, CAP Dr Vicenç Papaceit: Josep Lluis Fernández, CAP Salou: Cristina Ferrández, EAP Reus III: Manuel Prieto, EAP Reus IV: Teresa Basora.

\section{References}

1. Newby PK, Tucker KL \& Wolk A (2005) Risk of overweight and obesity among semivegetarian, lactovegetarian, and vegan women. Am J Clin Nutr 81, 1267-1274.

2. Alfieri MA, Pomerleau J, Grace DM \& Anderson L (1995) Fiber intake of normal weight, moderately obese and severely obese subjects. Obes Res 3, 541-547.

3. Ludwig DS, Pereira MA, Kroenke CH, Hilner JE, Van Horn L, Slattery ML \& Jacobs DR Jr (1999) Dietary fiber, weight gain, and cardiovascular disease risk factors in young adults. JAMA 282, 1539-1546.

4. Slavin JL (2005) Dietary fiber and body weight. Nutrition 21, 411-418.

5. Jenkins DJA, Kendall CWC, Axelsen M, Augustin LSA \& Vuksan V (2000) Viscous and nonviscous fibres, nonabsorbable and low glycaemic index carbohydrates, blood lipids and coronary heart disease. Curr Opin Lipidol 11, 49-56.

6. Schneeman BO (2002) Gastrointestinal physiology and functions. Br J Nutr 88, Suppl. 2, S159-S163.

7. Baer DJ, Rumpler WV, Miles CW \& Fahey GC Jr (1997) Dietary fiber decreases the metabolizable energy content and nutrient digestibility of mixed diets fed to humans. $J$ Nutr 127, 579-586.

8. Salas-Salvadó J, Bulló M, Pérez-Heras A \& Ros E (2006) Dietary fiber, nuts and cardiovascular diseases. Br J Nutr 96, Suppl. 2, S45-S51.

9. Pittler MH \& Ernst E (2001) Guar gum for body weight reduction: meta-analysis of randomized trials. Am J Med 110, $724-730$

10. Rodriguez-Moran M, Guerrero-Romero F \& Lazcano-Burciaga G (1998) Lipid- and glucose-lowering efficacy of Plantago Psyllium in type II diabetes. J Diabetes Complications 12, 273-278.

11. Birketvedt GS, Aaseth J, Florholmen JR \& Ryttig K (2000) Long-term effect of fibre supplement and reduced energy intake on body weight and blood lipids in overweight subjects. Acta Medica (Hradec Kralove) 43, 129-132.
12. Rossner S, Andersson IL \& Ryttig K (1988) Effects of a dietary fibre supplement to a weight reduction programme on blood pressure. A randomized, double-blind, placebo-controlled study. Acta Med Scand 223, 353-357.

13. Howarth NC, Saltzman E \& Roberts SB (2001) Dietary fiber and weight regulation. Nutr Rev 59, 129-139.

14. Jacobs ET, Giuliano AR, Roe DJ, Guillen-Rodriguez JM, Hess LM, Alberts DS \& Martinez ME (2002) Intake of supplemental and total fiber and risk of colorectal adenoma recurrence in the wheat bran fiber trial. Cancer Epidemiol Biomarkers Prev 11, 906-914.

15. National Heart Lung and Blood Institute: Obesity Education Initiative Expert Panel on the Identification, Evaluation, and Treatment of Overweight and Obesity in Adults (1998) Clinical guidelines on the identification, evaluation, and treatment of overweight and obesity in adults: the evidence report. Obes Res 6, S51-S210.

16. Salas-Salvadó J, Rubio MA, Barbany M, Moreno B \& Grupo Colaborativo de la SEEDO (2007) SEEDO 2007 Consensus for the evaluation of overweight and obesity and the establishment of therapeutic intervention criteria. Med Clin (Barc) 10; 128, 184-196.

17. Tuomilehto J, Voutilainen E, Huttunen J, Vinni S \& Homan K (1980) Effect of guar gum on body weight and serum lipids in hypercholesterolemic females. Acta Med Scand 208, 45-48.

18. Ryttig KR, Tellnes G, Haegh L, Boe E \& Fagerthun H (1989) A dietary fibre supplement and weight maintenance after weight reduction: a randomized, double-blind, placebo-controlled long-term trial. Int J Obes 13, 165-171.

19. Rigaud D, Ryttig KR, Angel LA \& Apfelbaum M (1990) Overweight treated with energy restriction and a dietary fibre supplement: a 6-month randomized, double-blind, placebocontrolled trial. Int J Obes 14, 763-769.

20. Makkonen M, Simpanen AL, Saarikoski S, Uusitupa M, Penttila I, Silvasti M \& Korhonen P (1993) Endocrine and metabolic effects of guar gum in menopausal women. Gynecol Endocrinol 7, 135-141.

21. Brown L, Rosner B, Willett WW \& Sacks FM (1999) Cholesterol-lowering effects of dietary fiber: a meta-analysis. Am $J$ Clin Nutr 69, 30-42.

22. Hylander B \& Rossner S (1983) Effects of dietary fiber intake before meals on weight loss and hunger in a weight-reducing club. Acta Med Scand 213, 217-220.

23. Birketvedt GS, Shimshi M, Erling T \& Florholmen J (2005) Experiences with three different fiber supplements in weight reduction. Med Sci Monit 11, I5-I8.

24. Walsh DE, Yaghoubian V \& Behforooz A (1984) Effect of glucomannan on obese patients: a clinical study. Int J Obes $\mathbf{8}$, 289-293.

25. Biancardi G, Palmiero L \& Ghirardi PE (1989) Glucomannan in the treatment of overweight patients with osteoarthrosis. Curr Ther Res 46, 908-912.

26. Cairella M \& Marchini G (1995) Evaluation of the action of glucomannan on metabolic parameters and on the sensation of satiation in overweight and obese patients. Clin Ter 146, 269-274.

27. Vita PM, Restelli A, Caspani P \& Klinger R (1992) Chronic use of glucomannan in the dietary treatment of severe obesity. Minerva Med 83, 135-139.

28. Anderson JW, Allgood LD, Lawrence A, Altringer LA, Jerdack GR, Hengehold DA \& Morel JG (2000) Cholesterol-lowering effects of psyllium intake adjunctive to diet therapy in men and women with hypercholesterolemia: meta-analysis of 8 controlled trials. Am J Clin Nutr 71, 472-479.

29. Salmeron J, Manson JE, Stampfer MJ, Colditz GA, Wing AL \& Willett WC (1997) Dietary fiber, glycemic load, and risk of noninsulin-dependent diabetes mellitus in women. JAMA $\mathbf{2 7 7}$, $472-477$. 
30. Montonen J, Knekt P, Jarvinen R, Aromaa A \& Reunanen A (2003) Whole-grain and fiber intake and the incidence of type 2 diabetes. Am J Clin Nutr 77, 622-629.

31. Rimm EB, Ascherio A, Giovannucci E, Spiegelman D, Stampfer MJ \& Willett WC (1996) Vegetable, fruit, and cereal fiber intake and risk of coronary heart disease among men. JAMA 275, 447-451.

32. Chandalia M, Garg A, Lutjohann D, von Bergmann K, Grundy SM \& Brinkley LJ (2000) Beneficial effects of high dietary fiber intake in patients with type 2 diabetes mellitus. $N$ Engl J Med 342, 1392-1398.

33. Wursch P \& Pi-Sunyer FX (1997) The role of viscous soluble fiber in the metabolic control of diabetes. A review with special emphasis on cereals rich in beta-glucan. Diabetes Care 20, $1774-1780$.

34. Ma Y, Griffith J, Chasan-Taber G, Olendzki B, Jackson E, Stanek E, et al. (2006) Association between dietary fiber and serum C-reactive protein. Am J Clin Nutr 83, 760-766.

35. Ajani U, Ford E \& Mokdad A (2004) Dietary fiber and C-reactive protein: findings from national health and nutrition examination survey data. $J$ Nutr 134, 1181-1185.

36. Jensen M, Koh-Banerjee P, Franz M, Sampson L, Gronbaek M \& Rimm E (2006) Whole grains, bran, and germ in relation to homocysteine and markers of glycemic control, lipids and inflammation. Am J Clin Nutr 83, 275-283. 